\title{
Spectral Analysis of Lamellae Evolution and Constraining Effects Aided by Nano- carbons: A Coupled Experimental and Simulation Study
}

\author{
Kenan Song ${ }^{\text {a }}$, Yiying Zhang ${ }^{\text {a }}$, Jiangsha Meng ${ }^{\text {a }}$, and Marilyn L. Minus ${ }^{\text {a,* }}$ \\ a Department of Mechanical and Industrial Engineering, Northeastern University, 360 \\ Huntington Avenue, Boston, MA, USA, 02115-5000 \\ *Corresponding Author, Email: m.minus@,neu.edu, Phone: (617) 373-2608
}

\begin{abstract}
The effects of filler concentration on processing-structure-property relationships in polymer composites with low nano-carbon $(\mathrm{nC})$ loadings $(<1 \mathrm{wt} \%)$ have been investigated. Fibrillar structure was observed under scanning electron microscopy (SEM), and confirmed quantitatively by X-ray measurements. A one-dimensional correlation function analysis of small-angle X-ray scattering (SAXS) data is used to track development for both the crystalline and amorphous regions in lamellae of the polymer matrix as a function of filler concentration and drawing temperature. Analysis for the filled poly(vinyl alcohol) (PVA) fibers demonstrates that the presence of the carbon nanochips (CNC) influences the organization and formation of lamellae stacking, leading to variations in composite fiber grain structure. An increase in grains per unit fibril volume and higher degree of chain orientation along the fiber axis was observed for the composites as compared to the control samples. Based on the fibrillar and lamellae dimensions of final stage fibers, mechanical simulations by finite element method (FEM) approaches were conducted on polymeric fibrils. Compared with molecular dynamics (MD) results, higher polymer constraining effects were related to increase of nano-particle inclusions. This work demonstrates the
\end{abstract}


significance of using spectroscopy analysis and coupled simulation methods to provide detail information regarding the property-structure relationship in nano-composite fibers.

\section{Keywords}

Nano-composite Fibers; Poly(vinyl alcohol); Small-angle X-ray scattering; MD; constraining effects

\section{Introduction}

Fundamental understanding regarding the processing-structure-property relationship in nano-composite fibers is necessary to develop these materials for eventual commercial applications [1-12]. To this end, many of the current research studies have focused on evaluating the property contributions of nano-filler in polymer-based composite fibers by modifying traditional composite mechanics (i.e., rule-of-mixture [13], Halpin-Tsai [14, 15]) models which consider both length and/or orientation effects. In most instances the polymer matrix is assumed to remain unchanged during fabrication processes. In addition, property 
changes related to uneven filler distribution and ineffective stress-transfer from the filler to the matrix due to shear-lag effects are not considered. For this reason, calculations for the effective filler contributions (i.e., effective modulus $\left(E_{\text {eff }}\right)$ and effective strength $\left(\sigma_{e f f}\right)$ ) are often overestimated and inconsistent based on simple superposition between matrix and filler properties. Both experimental and theoretical values determined for various nanocarbon materials are typically in the range of 500 to $1000 \mathrm{GPa}$ for modulus and 20 to 100 GPa for strength. These predictions are based on filler parameters including dimensions (i.e., diameter of tube, platelet/sheet width/thickness, number of walls depending on carbon nanotube (CNT) type, number of layers based on graphitic platelet thickness, and surface area), aspect ratio, as well as defective structural distributions [16]. Table 1 summarizes several studies that have aimed to estimate filler contribution in various nano-carbon based composites using these theoretical approaches.

Table 1. Representative effective elastic modulus $\left(E_{\text {eff }}\right)$ and strength $\left(\sigma_{\text {eff }}\right)$ values listed in the literature.

\begin{tabular}{|c|c|c|c|c|c|c|}
\hline Ref & $\begin{array}{l}\text { Nano- } \\
\text { Carbon }\end{array}$ & Polymer Matrix & Vol\% & $\begin{array}{c}E_{e f f} \\
(T P a)\end{array}$ & $\begin{array}{c}\sigma_{e f f} \\
(G P a)\end{array}$ & $\begin{array}{l}\text { Method of } \\
\text { Evaluation }\end{array}$ \\
\hline [17] & $\operatorname{SWNT}^{a}$ & $\begin{array}{l}\text { poly(methyl methacrylate) } \\
\text { (PMMA) }\end{array}$ & 0.008 & 9.6 & - & Halpin-Tsai \\
\hline [18] & $\mathrm{MWNT}^{b}$ & SU-8 resin & 0.06 & 1.3 & - & \multirow{7}{*}{$\begin{array}{l}\text { Rule-of- } \\
\text { mixture } \\
(\mathrm{ROM})\end{array}$} \\
\hline [19] & SWNT & $\begin{array}{l}\text { polyacrylonitrile (PAN) } \\
\text { carbonized carbon fibers }\end{array}$ & 2.8 & 2.6 & - & \\
\hline \multirow{2}{*}{ [20] } & $\mathrm{DWNT}^{c}$ & polyvinyl alcohol (PVA) & 0.8 & 5.1 & - & \\
\hline & MWNT & PVA & 0.7 & 1.4 & - & \\
\hline [21] & SWNT & PVA & 0.04 & - & 1000 & \\
\hline [22] & graphene & polyamide $(\mathrm{PI})$ & 0.5 & - & 125 & \\
\hline [23] & SWNT & pitch & 3.5 & - & 143 & \\
\hline
\end{tabular}


Previous studies have demonstrated that low loading of nano-carbons in the polymer fiber have the potential to influence changes in the matrix morphology as well as provide reinforcement toward producing mechanically robust fibers [6, 24-28]. However, these filler-matrix modifications in terms of the polymer morphology and microstructure have only been limitedly studied [29-31]. Therefore, examination of the matrix microstructures in composites becomes necessary toward understanding composite mechanical reinforcement mechanisms. Several characterization tools can be employed to track microstructural changes in the polymer matrix due to filler introduction. However, often times more than one tool may need to be coupled to provide representative information pertaining to the whole composite material. X-ray diffraction/scattering methods provide an avenue to measure the global average of nano-scale structure development for semicrystalline polymer materials. Specifically, wide-angle X-ray diffraction (WAXD) provides unit cell and crystallization information as well as texture analysis, while small-angle X-ray scattering (SAXS) is capable of delivering structural information at length scales ranging between 5 and $50 \mathrm{~nm}$. Proper analysis of such spectral data can provide appropriate detail for understanding the structural make-up of the polymer modified by nano-filler introduction as compared to the pristine matrix morphology.

Toward this effort, usage of one-dimensional correlation function has been performed by using SAXS data to study sub-fibrillar and lamellae structures in polymer materials [32]. Analysis of crystalline and amorphous thicknesses within lamellae structures have been conducted for polymer systems including poly(ether ether ketone) (PEEK) [33], polyethylene (PE) [34-36], poly(ethylene-co-1-octene) [37], poly(ethylene terephthalate) (PET) [38], poly(ethylene terephthalate/polyphenylene sulfide) (PET/PPS) bicomponent 
fibers [39], polyamide-6 [40-42], and poly(trimethylene terephthalate) [43]. Here in this work, this approach is applied for the first time to study polymeric microstructural dimensions in a poly(vinyl alcohol) (PVA) matrix. In terms of nano-composite research, PVA has been shown to undergo large microstructural changes due to the introduction of nano-carbons [44-47]. For this reason both PVA and PVA-based composite fibers with various nano-carbon concentrations are examined in order to map matrix structural evolution as a function of filler content.

In addition to experimental tracking of polymer matrix changes, their contribution to the composite performance should also be followed. This can be achieved by both experimental and theoretical routes. As mentioned, theoretical evaluation should include the matrix differences due to filler content for accurate analysis. Currently, one of the challenges that simulation theorists encounter is the ability to obtain practical and physically meaningful materials microstructural parameters [48]. Such constraints require a detailed view provided by experimentation for the composite matrix morphology changes. Theoretical modeling based on micro-mechanics and nano-mechanics can be accomplished by using computational methods at either the continuum or the atomistic level. Continuum models typically involve the usage of the finite element methods (FEM), whereas atomistic models usually involve molecular dynamics (MD) [48]. In this work, for complete analysis of matrix changes and filler contributions in the loaded composites, the experimentally obtained polymeric structural parameters are coupled to mechanics models. The study uses both FEM and MD approaches to link intrinsic properties between the nano-scale and macro-scale in order to show constraining effects from nano fillers on molecular polymer 
chains, which ultimately induce mechanical properties beyond theoretical predictions as obtained from simple composite models.

\section{Materials and methods}

\subsection{Materials}

As-produced, carbon nano-chips (CNC) (i.e., flattened FWNT with similar length and width and average aspect ratio $\sim 1$, consisting of six to eight walls, and purity $>99 \mathrm{wt} \%$, purchased from Catalytic Materials LLC) and Mowiol 56-98 PVA $\left(M_{w} \sim 105,600 \mathrm{~g} \cdot \mathrm{mol}^{-1}\right.$, degree of hydrolysis $98.4 \pm 0.4 \mathrm{~mol} \%$, residual acetyl content $1.5 \pm 0.4 \mathrm{wt} \%$, obtained from Kuraray America Inc.) were used for spinning control and composite fibers.

\subsection{Sample Preparation}

Spinning dopes were prepared by dissolution of PVA to a final solid concentration of $10 \mathrm{wt} \%$. For composite dopes the final solid content of CNC to PVA were $0.125,0.25,0.5$, and $1 \mathrm{wt} \%$, respectively. All fibers were spun using a flow-based gel-spinning approach [44]. As-spun fibers were subsequently heat-drawn on rectangular hot plate (10 inches by 1 inch) at three temperature stages corresponding to $100{ }^{\circ} \mathrm{C}$ (Stage-I), $160{ }^{\circ} \mathrm{C}$ (Stage-II), and $200^{\circ} \mathrm{C}$ (Stage-III).

\subsection{Sample Characterization}

Tensile tests were conducted using a dynamic mechanical analyzer (RSA-G2 series, manufactured by TA Instruments) with a gauge gap of $20 \mathrm{~cm}$ and extension rate of 0.05 $\mathrm{mm} \cdot \mathrm{min}^{-1}$, where 15 fibers were tested for each sample batch. Wide-angle X-ray diffraction (WAXD) was performed using a Rigaku RAPID II curved detector X-ray diffraction (XRD) system equipped with a $3 \mathrm{~kW}$ sealed tube source (voltage $40 \mathrm{kV}$ and current $30 \mathrm{~mA}$ ) manufactured by Rigaku Americas Corporation. XRD curve fitting and analysis was 
performed using software's PDXL 2 (version 2.0.3.0) and 2DP (version 1.0.3.4) to obtain azimuthal integration data as well as peak widths (i.e., full-width at half maximum (FWHM)). Instrumental effects were corrected by subtracting a background air scattering curves from the measured data. Small-angle X-ray scattering (SAXS) were performed using a SMAX3000 system with high-brilliance 007HF source with $\mathrm{CuK}_{\alpha}$ radiation (operation voltage $40 \mathrm{kV}$ and current $30 \mathrm{~mA}, 147 \mathrm{~kW}$ ), equipped with a $200 \mathrm{~nm}$ multi-wire twodimensional detector (manufactured by Rigaku Americas Corporation). The spot size of the primary X-ray beam at the sample position is approximately $200 \mu \mathrm{m}$ in diameter. The sample-to-detector distance for the system is $1525 \mathrm{~mm}$. At this distance the effective scattering vector $(q)$ range is 0.03 to $0.27 \AA^{-1}$. SAXS patterns were analyzed using the Rigaku GUI software to obtain $q$ versus intensity $(I(q))$ curves, and two-dimensional scattering intensity distribution profiles. A field-emission high-resolution scanning electron microscope (SEM) (Zeiss Supra 25, accelerating voltage $5 \mathrm{kV}$ ) was used to image the internal fibril structures. All samples were sputtered coated with a thin chromium layer (i.e., coating ranged from 15 to $20 \mathrm{~nm}$ ) using a Gatan high-resolution ion beam coater for image analysis.

\section{Results and Discussion}

\subsection{Mechanical Property Analysis for the Nano-Composite Fibers}

The experimentally measured mechanical properties for both PVA and PVA/CNC fibers at drawing Stages III $\left(200{ }^{\circ} \mathrm{C}\right)$ are listed in Table 2. By examining the property variations for the fibers, an increasing trend is observed for both elastic modulus $(E)$ and tensile strength $(\sigma)$ when comparing the control fibers with the composites up to $0.5 \mathrm{wt} \%$ loading. At filler concentrations of $1 \mathrm{wt} \%$, the fibers were found to show some 
inconsistencies in the property trend. This decrease in property is due to processing difficulties related to controlling the filler dispersion in the fiber as loading increases. These fiber properties demonstrate the ability of incorporating low filler loadings for mechanical improvements. However, examination of the reinforcement contribution pertaining to such a low volume fraction of filler shows that it alone cannot account for the experimentally measured properties. This recognition leads to an investigation of the composite fiber structure/morphology. Unique matrix features due to the addition of nano-filler are assumed to play a dominant role toward the property trends observed in the composites. These matrix changes include bulk grain morphology, molecular crystallization, and polymer chain orientation. To understand the influence of the matrix properties on the bulk composite both computation and experimental evaluations are coupled.

Table 2. Average mechanical properties for final processed PVA control and PVA/CNC composite fibers.

\begin{tabular}{c|c|c|c}
\hline \hline CNC Loading (wt\%) & ${ }^{\mathbf{a}} \boldsymbol{E}$ (GPa) & ${ }^{\mathbf{b}} \boldsymbol{\sigma ( G P a )}$ & ${ }_{\boldsymbol{\varepsilon}(\boldsymbol{\%})}$ \\
\hline \hline 0 & $27.20 \pm 3.48$ & $1.18 \pm 0.35$ & $6.88 \pm 2.33$ \\
\hline 0.125 & $39.51 \pm 8.32$ & $1.52 \pm 0.24$ & $5.24 \pm 0.80$ \\
\hline 0.25 & $47.61 \pm 7.57$ & $1.42 \pm 0.18$ & $5.45 \pm 1.20$ \\
\hline 0.5 & $60.45 \pm 5.95$ & $2.20 \pm 0.27$ & $7.46 \pm 3.97$ \\
\hline 1 & $57.96 \pm 4.91$ & $1.61 \pm 0.12$ & $4.31 \pm 0.20$ \\
\hline \hline
\end{tabular}

${ }^{a}$ elastic modulus, ${ }^{b}$ tensile strength, ${ }^{c}$ elongation-to-break measured from static tensile tests.

3.2.Molecular Dynamics Evaluation for PVA Baseline Parameters

In semi-crystalline polymeric materials both crystalline and amorphous regions are typically present. These crystalline and amorphous regions exhibit a wide variation in mechanical performance in terms of their elastic modulus, tensile strength and Poisson's 
ratio. Typically properties in the crystalline regions can be characterized by the crystal lattice. This region separated from the amorphous zones is well defined, where the elastic constants can be calculated theoretically based on inter-atomic forces or potentials. An axial modulus of the polymer crystals is typically derived based on changes in the lattice spacing/strains when an oriented fiber is subjected to a tensile stress. The lattice changes are typically measured using X-ray diffraction [49-53]. Previously, crystals for the PVA polymer have been measured using this approach along the unit cell $b$-axis (i.e., fiber axis) and exhibit a theoretical modulus of $\sim 255 \mathrm{GPa}[54,55]$. Using a similar approach the theoretical transverse (i.e., along the unit cell a/c-axis) modulus was calculated to be $\sim 9$ GPa [56], where inter/intra-chain hydrogen bonding is determined to play a role.

Comparatively, the behavior of amorphous regions within a polymeric fiber can vary greatly with temperature and/or level of preferred ordering/density variations. For this reason, pinpointing the exact mechanical contribution as it pertains to the amorphous areas is a challenge. The fiber properties shown in Table 2 are evaluated at room temperature ( 25 ${ }^{\circ} \mathrm{C}$ ). This temperature is much lower than the glass transition for PVA (i.e., $T_{g}$ ranges from $\sim 63$ to $98^{\circ} \mathrm{C}$ based on experimental dynamic mechanical measurements performed on the fibers $[44,45])$. Therefore, it is assumed that the amorphous regions are in a glassy state. Within the linear elastic region, the initial modulus of the amorphous regions is primarily dependent on the conformation (i.e., entropic state) of polymer chains. For this reason, examinations related to the bulk material modulus will limit the region of analysis to the linear tension region (i.e., initial portion of the stress-strain curve).

Initial MD studies were performed here to examine the mechanical response of the PVA amorphous regions in a tension simulation. A simplified PVA coarse-grain model was 
used for these simulations. Each coarse-grained bead represents one monomeric unit of PVA [57]. The modeled amorphous polymer matrix contains 10 PVA chains with 1000 monomers for each chain. The entire system was generated using a self-avoid random walk method with the nearest neighbor distance of $2.6 \AA$. Initial chain configurations were obtained by first heating up the system to $500 \mathrm{~K}$ in $0.1 \mathrm{~ns}$ (i.e., 10000 time-steps) and holding it at this temperature under NPT ensemble for $0.5 \mathrm{~ns}$. This was followed by a cooling step from $500 \mathrm{~K}$ to $100 \mathrm{~K}$ in $0.1 \mathrm{~ns}$, which included another stabilization step at 100 $\mathrm{K}$ for $0.5 \mathrm{~ns}$. After obtaining the final configuration, a strain rate of $10^{9} \mathrm{~s}^{-1}$ was used to deform the simulation box unidirectionally, while calculating and recording the strain and tensile stress captured from the system.

The first round of simulated tensile tests pulled the entire box to a strain value of 40 in order to ensure the complete failure (by chain breaking) of the matrix (Figure 1a). By analyzing the stress-strain curve obtained from this preliminary testing, a range of strain values was determined between 10 and 15 (Figure 1a) before initial material failure. The second round of tests pulled the simulation box to a specific strain corresponding to the experimental fiber draw ratio during processing without inducing fracture of the matrix. Then the whole system was subsequently re-equilibrated using both conjugate gradient and steepest descent minimization algorithms, followed by a NVE ensemble with limited 0.02 $\AA$ displacements per time-step for 0.2 ns. After this additional stabilization step, the matrix was then subjected to another round of pulling using the same deformation parameters pertaining to the first tests (i.e., strain rate of $10^{9} \mathrm{~s}^{-1}$ ), while recording the strain and stress values (Figure 1b). 

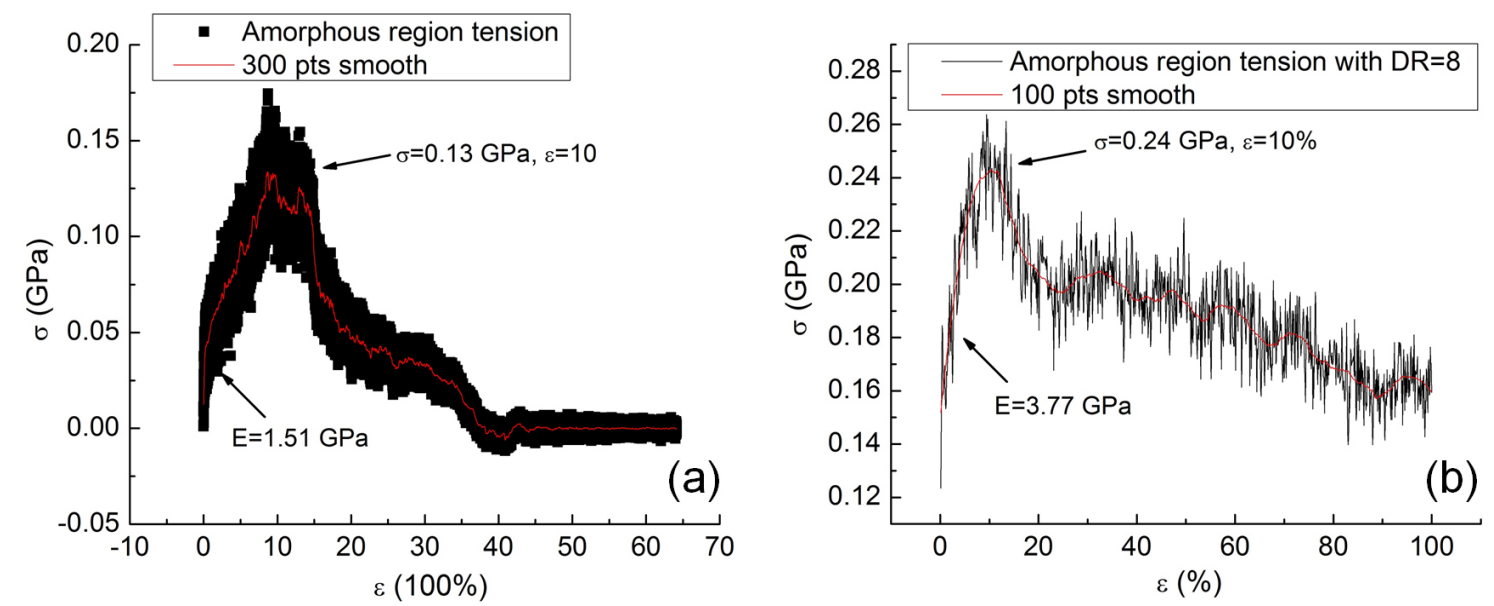

Figure 1. Stress-strain simulations for PVA chains in an amorphous conformation under the conditions of (a) tension without pre-applied loading, and (b) tension after drawing the matrix to a drawn ratio (DR) of 8 .

Based on the baseline MD studies for the PVA amorphous regions, Figure 1a showed an effective draw ratio of up to 10 to 15 before slippage and appearance of defects (i.e., void regions) in the matrix. This result is also consistent with experimentally measured draw ratios (i.e., 10-15). In comparison, Figure $1 \mathrm{~b}$ shows that small increases for both the elastic modulus and yield/tensile strength are found if a pretension (i.e., draw ratio to 8 before tension) is introduced in the amorphous matrix. These parameters for the amorphous regions based on these simulations are used in subsequent FEM models discussed in this work. However, it is important to note that the MD simulations do not account for any presence of filler particles in the amorphous polymer. As discussed, it has been observed that the nano-fillers may influence matrix changes in the materials. Therefore, detailed analysis of the nano-composite fiber is required to learn what changes do occur that may be unique to the nano-composite system. Such experimental insight is important for the determination of parameters and assumptions needed for theoretical evaluation. 


\subsection{Experimental Structural Analyses for Control and Composite Fibers}

SEM analysis is used to image the internal structure for all drawn fibers (Figure 2). It is clear that both control and composite fibers exhibit a distinctive fibrillar structure. This type of structure is expected for highly drawn/oriented fibers, with corresponding highperformance properties (Table 2). Figure 3 shows a schematic representing the general fibrillar structure in a typical fiber as well as the distribution of crystalline and amorphous regions within the fibrils and subsequent lamellae. $D_{f}$ and $L_{f}$ are the diameter and length of the fibrils, respectively. $D_{L}$ and $L_{L} / L_{p}$ are the average single lamella diameter and height. $D_{l}$ is a unit lamellae diameter, and is typically inclusive of multiple lamellae stacks. $L_{c}$ and $L_{a}$ are the single lamella crystalline and amorphous height. $D_{c}$ and $D_{a}$ are the diameters for the crystalline and amorphous portions of a single lamella. These various dimensions are evaluated for the composite fibers using X-ray diffraction and scattering analysis.

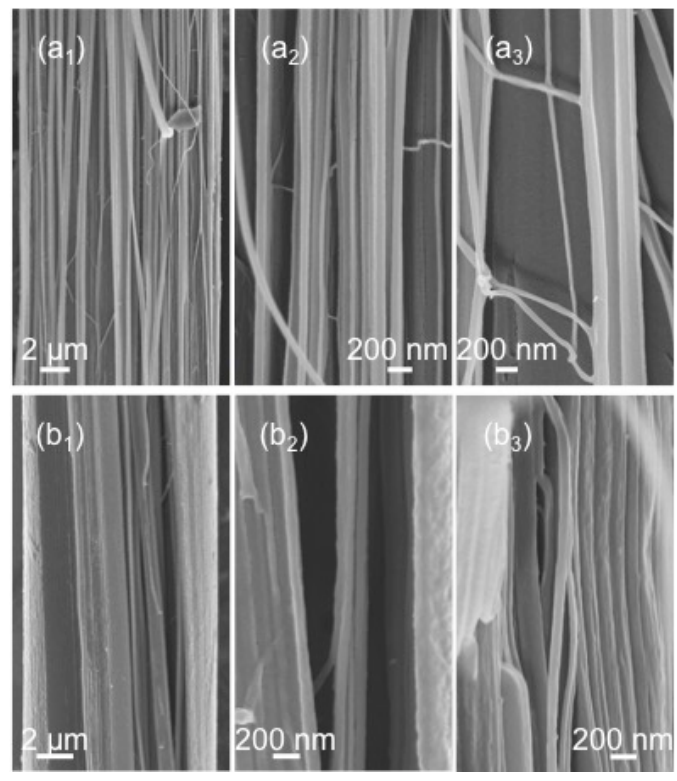

Figure 2. Scanning electron micrographs showing representative internal fibrillar structures of the fully drawn control ( $a_{1}$ to $\left.a_{3}\right)$ and composite fibers $\left(b_{1}\right.$ to $\left.b_{3}\right)$. 
(a)

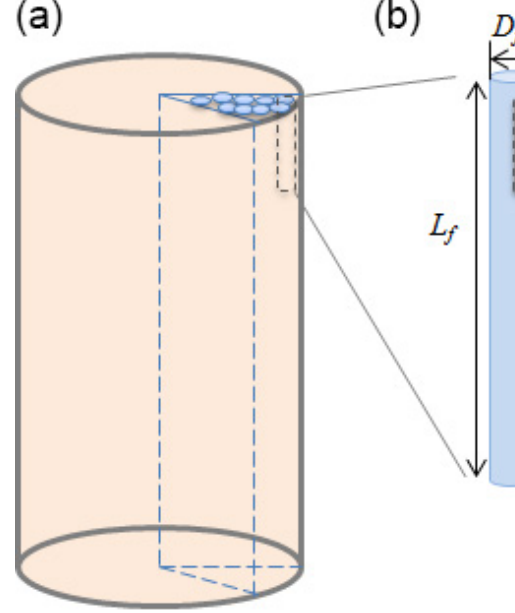

Fiber (b)

Fibril (c)

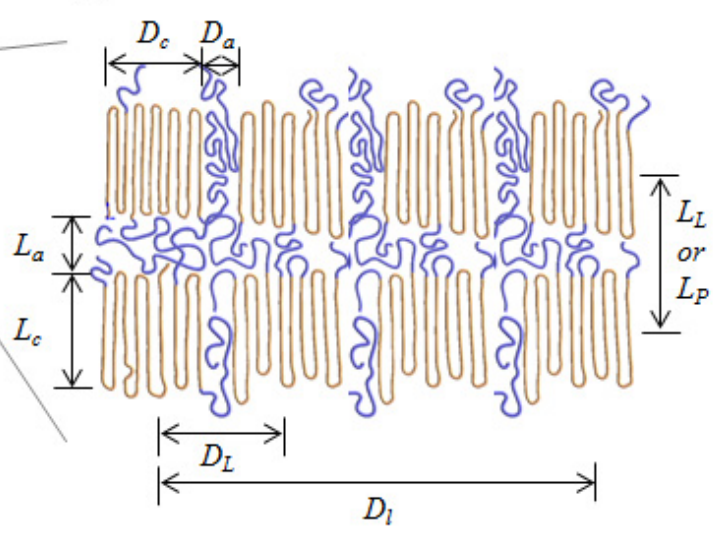

Lamellar structure

Figure 3. Schematic models for the general hierarchical fiber structure exhibited by the PVA and PVA/CNC fibers showing, (a) fibrillar structure present in fiber; (b) a single fibril which consists of lamellae stacks; and (c) magnified view of the lamellae stacks showing both representative crystalline, and amorphous regions. $L_{L}$ and $L_{p}$ represent the same lamellae stack dimension and are determined by experimental $\left(L_{L}\right)$ and theoretical $\left(L_{P}\right)$ approaches, respectively.

SAXS data is used to evaluate size domains ranging from 5 to $50 \mathrm{~nm}$ pertaining to the amorphous and crystalline regions within the lamellae and fibrillar structures in the fibers. Typically the SAXS patterns exhibit two distinct features (i) an equatorial diffuse scattering (EDS) streak and (ii) discrete lobes/lamellae meridional peaks (LMP) along the meridional direction. The EDS from the fibers develops due to elongated cylindrical objects (e.g., voids or fibrils) [58] in the samples. Typically overall scattering due to widely dispersed elongated voids occurs at scattering vector $\left(q_{\text {avg }}\right)$ values of less than $0.01 \AA^{-1}$, while a weaker scattering due to interfibrillar interference occurs at scattering vector more than $0.01 \AA^{-1} . q_{\text {avg }}$ is related to the scattering angle $(\theta)$ by the relationship provided in Equation 1, where $\lambda$ is the $\mathrm{X}$-ray wavelength of $0.15418 \mathrm{~nm}$. 


$$
q_{\text {avg }}=\frac{4 \pi \sin \theta}{\lambda}
$$

The LMP arises from the lamellae stacks in the fibers. Both the EDS and LMP data is used to analyze the overall fibrillar structure in the PVA and PVA/CNC fibers. The scattering vector $\left(q_{\text {avg }}\right)$ can be separated with respect to both EDS and LMP directions and referred to as $q_{1}$ and $q_{2}$, respectively (Figure 4a).
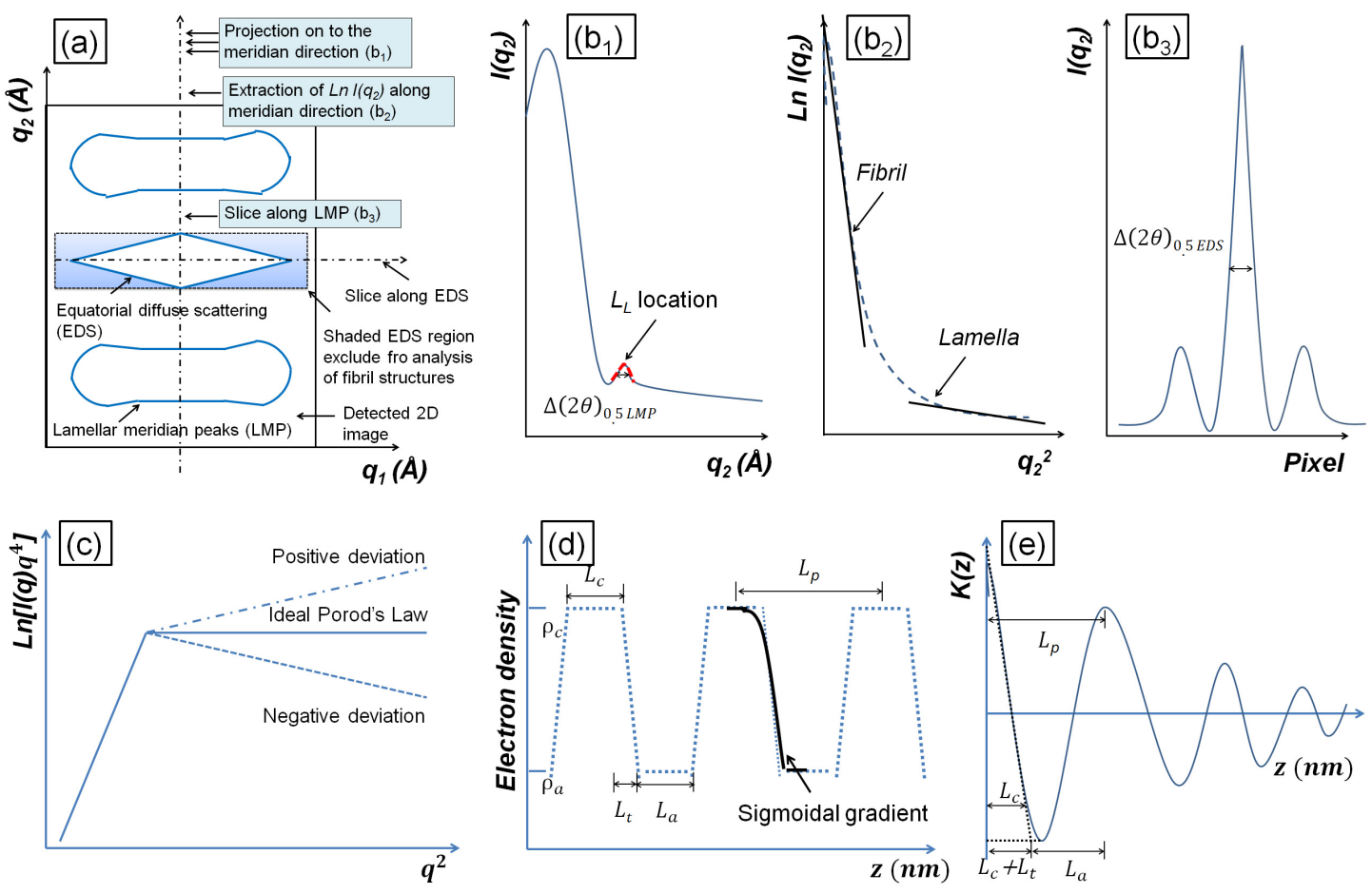

Figure 4. (a) Schematic of 2D SAXS pattern identifying various sectors/projections of interest related to fibril and lamella dimensions. Schematic plots associated with the sector/projection scans shown in (a) for $\left(b_{1}\right)$ one-dimensional scattering profile along LMP direction providing lamella $\left(L_{L}\right)$ dimensions; $\left(b_{2}\right) \ln \left(I\left(q_{2}\right)\right) v s . q_{2}{ }^{2}$ plot used for Guinier slope fitting to determine average lateral dimensions of fibrils and lamellae; and $\left(b_{3}\right)$ slice projection along LMP. (c) Plot illustrating the ideal Porod's law curve as well as respective positive and negative deviations. (d) Relationship between the electron density for both crystalline, amorphous, and transition regions with respect to their real space dimensions $(z)$ within the lamella. (e) Expected plot for the one-dimensional correlation function $(K(z))$ and its relationship to the dimensions for the crystalline $\left(L_{c}\right)$, amorphous $\left(L_{a}\right)$, and transition $\left(L_{t}\right)$ regions within the lamella $\left(L_{P}\right)$. 
Figure 5a shows the representative 2D-SAXS patterns for the fibers at each hot-stage drawing stage. As expected, the patterns show the development of stronger LMP scattering arising from the formation of well-defined lamellae stacks (i.e., grain structure) normal to fiber axis. The two-point lobe pattern is indicative of lamellae structure formations, with its surface being perpendicular to the fiber axis and/or uncorrelated stacking in adjacent fibrils [58]. One-dimensional intensity-scattering vector profiles $\left(I\left(q_{2}\right)\right.$ vs. $q_{2}$ curves $)$ are provided in Figure 5b. Bar plots showing the increasing of the lamellae stack height as a function of fiber drawing are also shown in Figure 5c. The lamellae stack height $\left(L_{L}\right)$ is estimated from Bragg's law using the $q_{2}$ position for the observed meridional peak position in the SAXS pattern (Equation 2). From this analysis it was found that the $L_{L}$ increased as a function of fiber drawing temperature and with addition of the $\mathrm{CNC}$. The fully drawn composite fibers (i.e., Stage-III, $200^{\circ} \mathrm{C}$ ) exhibit a $L_{L}$ increase up to $16.4 \mathrm{~nm}$ as compared to the control fiber of $14.8 \mathrm{~nm}$.

$$
L_{L}=2 \pi / q_{2}
$$


(a) $100^{\circ} \mathrm{C}$
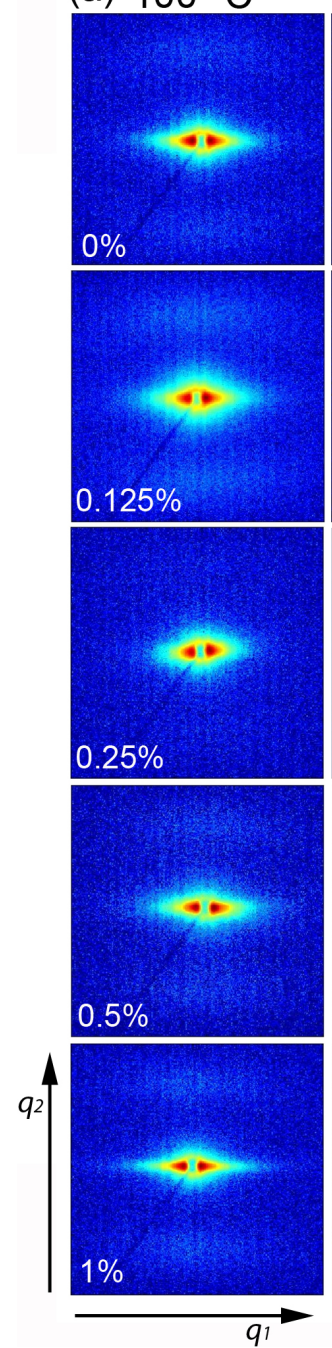

$160^{\circ} \mathrm{C}$
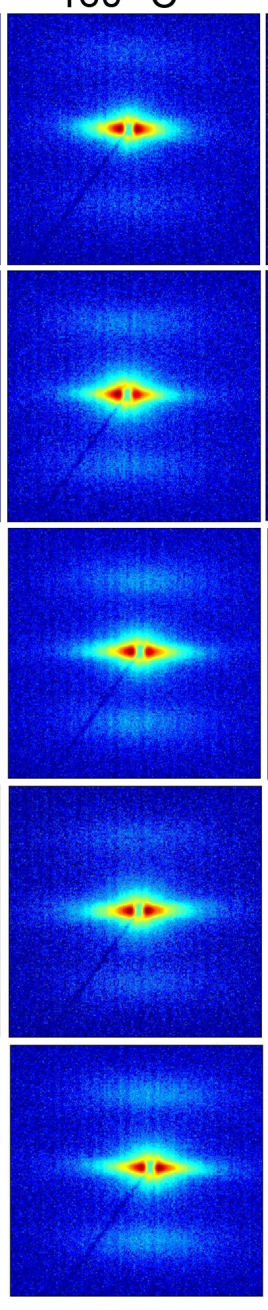

$200^{\circ} \mathrm{C}$
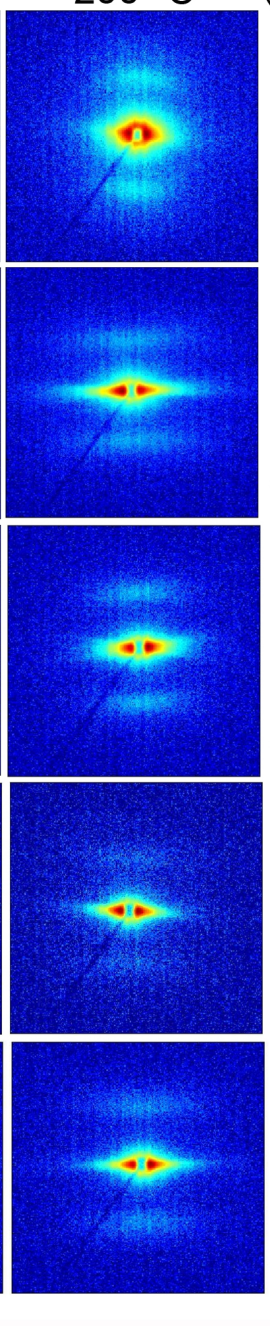

(b)
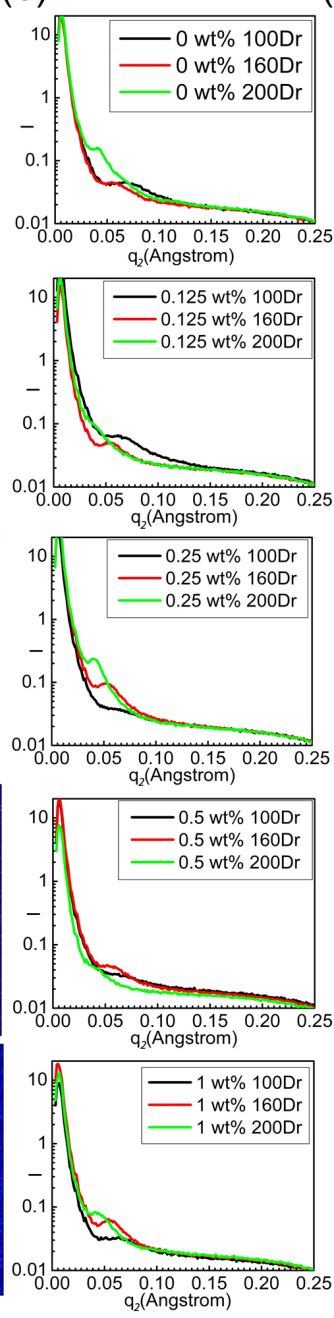

(c)
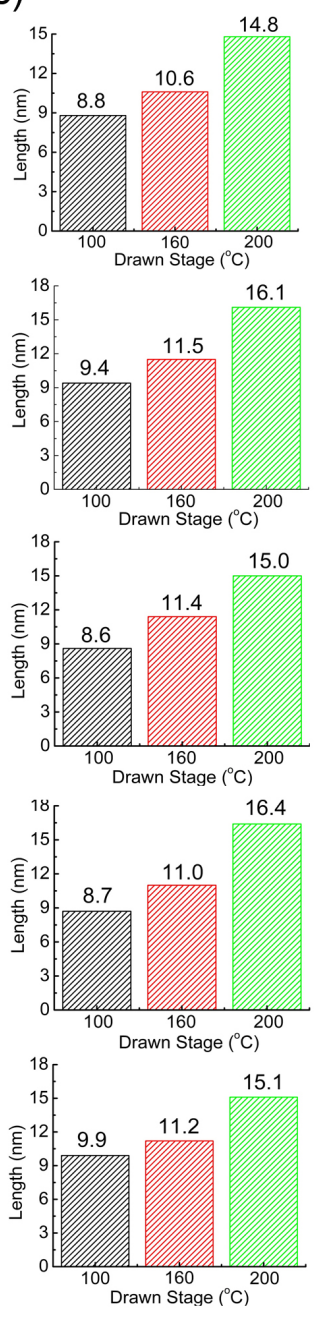

Figure 5. (a) Small-angle X-ray scattering patterns showing the development of the longorder lamellae spacing as a function of hot-drawing temperatures. (b) Plots showing the one-dimensional $I\left(q_{2}\right)$ vs. $q_{2}$ scattering profiles as a function of drawing for all fiber samples. (c) Bar plots showing the increase of the lamellar stack height $\left(L_{L}\right)$ as a function of fiber drawing stages shown for all fibers.

Based on calculations for the long-order dimensions (Figure 5, and Tables 3 and 4), it was observed that during drawing the lamellae and fibrillar dimensions in the fibers exhibit a pronounced change (i.e., SAXS analysis), while the sub-unit structures pertaining to the crystal unit cell (i.e., WAXD analysis) are less obvious (Table 3). This observation suggests 
that the distribution of both amorphous and crystalline regions in the lamellae structures may impact these experimental observations. For this reason, to better understand the distribution of the inter-lamellae and the inter-fibrillar amorphous/crystalline regions in fibers, various segments of the SAXS 2D pattern were analyzed (Figure 5a) to quantify all sub-dimensions (Figure 3).

Table 3. List of adjacent chain packing size (i.e., (101) peak) and lamellae stack height $\left(L_{L}\right)$ as measured from SAXS and WAXD data analysis.

\begin{tabular}{|c|c|c|}
\hline $\begin{array}{l}\text { Filler loading } \\
\quad(w t \%)\end{array}$ & $\begin{array}{c}\text { WAXD (101) - Crystal Size } \\
(\mathrm{nm})\end{array}$ & $\begin{array}{c}L_{L} \\
(\text { Peak position of Meridional lobe, } \\
\text { nm) }\end{array}$ \\
\hline \multicolumn{3}{|c|}{ Stage-I $100^{\circ} \mathrm{C}$} \\
\hline 0 & 4.9 & 8.8 \\
\hline 0.125 & 4.7 & 9.4 \\
\hline 0.25 & 4.7 & 8.6 \\
\hline 0 & 4.3 & 8.7 \\
\hline 1 & 4.8 & 9.9 \\
\hline \multicolumn{3}{|c|}{ Stage-II $160^{\circ} \mathrm{C}$} \\
\hline 0 & 5.7 & 10.6 \\
\hline 0.125 & 5.7 & 11.5 \\
\hline 0.25 & 5.5 & 11.4 \\
\hline 0.5 & 5.9 & 11.0 \\
\hline 1 & 5.8 & 11.2 \\
\hline \multicolumn{3}{|c|}{ Stage-III $200^{\circ} \mathrm{C}$} \\
\hline 0 & 6.0 & 14.8 \\
\hline 0.125 & 6.8 & 16.1 \\
\hline 0.25 & 7.5 & 15.0 \\
\hline 0.5 & 7.6 & 16.4 \\
\hline 1 & 7.2 & 15.1 \\
\hline
\end{tabular}

A sector averaged equatorial scan (Figure 4a) can be used to determine the distribution for the fibril $\left(D_{f}\right)$ and corresponding lamella $\left(D_{L}\right)$ diameter in the fibers. This information is obtained from the Guinier slope plot given by $\ln \left(I\left(q_{2}\right)\right) v s . q_{2}^{2}$ (Figure $\left.4 \mathrm{~b}_{2}\right)$, and is used to 
solve Equation 3. The fibril and lamella dimensions are obtained by examining different $q_{2}^{2}$ ranges (Figure $\left.4 b_{2}\right)$.

$$
I(q)=I(0) \exp \left(-q_{2}{ }^{2} r^{2} / 5\right)
$$

The value of $r$ denotes the radius of gyration for the scattering particles, and corresponds to the radius of the fibrils $\left(D_{f}\right)$ and lamella $\left(D_{L}\right)$. Based on this analysis, $D_{f}$ was found to range from 47 to $55 \mathrm{~nm}$ for control and composite fibers, where the composite samples exhibit the largest dimensions (Table 4). It must be mentioned that the Guinier approximation is strictly applicable to mono-disperse systems only when $q_{2} \cdot r<1$, which is applied in the measurements here. This analysis also shows that each fibril consists of multiple lamellae along the lateral direction (Table 4). The diameter of the correlated lamellae stacks $\left(D_{l}\right)$, was determined using Scherrer's method (Equation 4 [59]).

$$
D_{l}=0.94 \lambda /\left[\Delta(2 \theta)_{0.5 L M P}\right]
$$

The full-width at half maximum $\left(\Delta(2 \theta)_{0.5, L M P}\right)$ data extracted from the slice projection along LMP (Figure $4 b_{1}$ ) and is expressed in radians. It is observed that as the drawing stage proceeds lamellae development improves (Tables 3 and 4).

The length of the fibrils may be approximated based on analysis of the EDS, and is accomplished by taking a longitudinal slice along the LMP through the scattering profile as shown in Figure $4 b_{3}$. Based on this information the length of the fibrils $\left(L_{f}\right)$ was determined using Equation 5. 


$$
L_{f}=0.94 \lambda /\left[\Delta(2 \theta)_{0.5 E D S} \cos \theta\right] \approx 0.94 \lambda F / \sqrt{\left(\Delta(2 \theta)_{0.5 E D S}\right)^{2}-b^{2}}
$$

$\theta$ is the Bragg angle, the sample to detector distance $(F)$ is $1525 \mathrm{~mm}$ and $b$ corresponds to the instrumental broadening.

Table 4. List of the values for the various structural parameters pertaining to the fibrillar structures in both control and composite fibers as determined from SAXS data analysis.

\begin{tabular}{|c|c|c|c|c|}
\hline $\begin{array}{l}\text { Filler loading } \\
\text { (wt\%) }\end{array}$ & $\begin{array}{c}D_{f} \\
\text { (Gunier Slope } \\
\text { EDS, nm) } \\
\end{array}$ & $\begin{array}{c}D_{l} \\
\text { (Scherrer } \\
\text { Equation, } n \mathrm{~m}) \\
\end{array}$ & $\begin{array}{c}D_{L} \\
\text { (Guinier Slope } \\
\text { LMP, nm) } \\
\end{array}$ & $\begin{array}{c}\boldsymbol{L}_{f} \\
(\boldsymbol{\mu} \boldsymbol{m})\end{array}$ \\
\hline \multicolumn{5}{|c|}{ Stage-I $100^{\circ} \mathrm{C}$} \\
\hline 0 & 49.6 & 15.2 & 4.2 & 0.89 \\
\hline 0.125 & 50.0 & 16.3 & 5.0 & 0.89 \\
\hline 0.25 & 50.0 & 9.1 & 3.0 & 0.82 \\
\hline 0 & 50.8 & 15.2 & 4.2 & 0.94 \\
\hline 1 & 49.4 & 20.0 & 4.6 & 0.90 \\
\hline \multicolumn{5}{|c|}{ Stage-II $160^{\circ} \mathrm{C}$} \\
\hline 0 & 49.6 & 20.3 & 6.2 & 0.96 \\
\hline 0.125 & 54.0 & 22.5 & 6.8 & 0.84 \\
\hline 0.25 & 53.2 & 24.6 & 7.2 & 0.90 \\
\hline 0.5 & 51.8 & 20.3 & 6.0 & 1.07 \\
\hline 1 & 51.8 & 26.6 & 6.6 & 1.11 \\
\hline \multicolumn{5}{|c|}{ Stage-III $200^{\circ} \mathrm{C}$} \\
\hline 0 & 47.2 & 23.1 & 10.6 & 0.67 \\
\hline 0.125 & 54.6 & 20.7 & 9.8 & 1.08 \\
\hline 0.25 & 52.2 & 33.5 & 10.6 & 0.96 \\
\hline 0.5 & 54.0 & 19.0 & 5.6 & 1.04 \\
\hline 1 & 52.4 & 24.8 & 7.6 & 0.93 \\
\hline
\end{tabular}

This analysis also show that there are changes in the fibril diameter/length corresponding to each hot-drawing stage, which may be related to the rearrangement of crystals and polymer chains due to the thermal energy and stress applied during this process. 
In general it is found that the control fibers have a shorter fibril length as compared to the composites. The overall fibril diameters $\left(D_{f}\right)$ are also larger for the composites as compared to the control fibers. This indicates that the fibrillar structure is more developed in the composite fibers, and may be due to the presence of the rigid $\mathrm{CNC}$, which can act as template for polymer ordering [45], and higher hot-stage drawing ratios.

$D_{l}$ and $D_{L}$ were found to be smaller for the composites as compared to the control fibers. These structural features may indicate that the presence of the CNC fillers can provide more crystal nucleation sites. The (101) crystal size measured by WAXD also provides information regarding chain packing perpendicular to the fiber axis (Table 4). These crystal size values are generally slightly smaller than those of $D_{L}$, and this is due to the existence of both amorphous and crystalline regions present in each lamella. For this reason, additional theoretical analysis is performed using a one-dimensional correlation function, $K(z)$, to determine the distribution of the amorphous and crystalline domains in each lamellae stack. Equations 6 and 7 describe the modified correlation function (i.e., for anisotropic materials) used in this work [42].

$K(z)=\int_{0}^{\infty} I_{1}\left(q_{2}\right) \cos \left(z q_{2}\right) d q_{2} / \int_{0}^{\infty} I_{1}\left(q_{2}\right) d q_{2}$

where,

$I_{1}\left(q_{2}\right)=\int_{0}^{\infty} I_{1}\left(q_{1}, q_{2}\right) d q_{1} / 4 \pi^{2}$ 
$q_{1}$ and $q_{2}$ are the scattering vectors along equatorial and meridional directions, respectively, and $z$ represents the distance/dimension in real space (Figure 4a). It must be mentioned that for a model of lamellae stacks the correlation function $(K(z))$ containing the basic morphological information is based on unoriented samples of a partially crystalline polymer, where the lamellae structure is isotropically distributed. Therefore, the multiplication of $q_{1}^{2}$ to $I(q)$ should be performed for the oriented system. To this end, Equations 6 and 7 are modified and shown by Equations 8 and 9, respectively. The SAXS data was extrapolated to fit the Porod's law (Figure 4c), and integrated in Equation 8. Figure $4 \mathrm{~d}$ shows a scheme of the electron density $(\rho)$ profile for alternating amorphous $\left(\rho_{a}\right)$ and crystalline $\left(\rho_{c}\right)$ layers, respectively. The dotted line corresponds to a pseudo-two-phase structure showing the two major amorphous and crystalline phases with average dimensions $L_{a}$ and $L_{c}$ (Figure $4 \mathrm{~d}$ ). The linear electron density gradient corresponds to the thickness of a transition region $\left(L_{t}\right)$, where the polymer molecule is considered neither part of the crystalline nor amorphous phase. The values for $L_{a}, L_{c}$, and $L_{t}$, can be extracted quantitatively from $K(z)$ (Figure 4e). The calculated data is listed in Table 5.

$K(z)=\int_{0}^{\infty} I_{1}\left(q_{2}\right) q_{1}^{2} \cos \left(z q_{2}\right) d q_{2} / \int_{0}^{\infty} I_{1}\left(q_{2}\right) d q_{2}$

Where,

$I_{1}\left(q_{2}\right)=\int_{0}^{\infty} I_{1}\left(q_{1}, q_{2}\right) q_{1}^{2} d q_{1} / 4 \pi^{2}$ 
Table 5. Theoretically determined lamellae parameters based on the one-dimensional correlation function analysis of SAXS data.

\begin{tabular}{|c|c|c|c|c|}
\hline Filler loading (wt\%) & $\begin{array}{c}L_{t} \\
(\mathrm{~nm})\end{array}$ & $\begin{array}{c}L_{a} \\
(n m)\end{array}$ & $\begin{array}{c}L_{c} \\
(n m)\end{array}$ & $\begin{array}{c}L_{p} \\
(\mathrm{~nm})\end{array}$ \\
\hline \multicolumn{5}{|c|}{ Stage-I $100^{\circ} \mathrm{C}$} \\
\hline 0 & 1.0 & 3.5 & 4.2 & 8.7 \\
\hline 0.125 & 1.3 & 3.5 & 4.2 & 9.0 \\
\hline 0.25 & 1.3 & 4.0 & 3.7 & 9.0 \\
\hline 0.5 & 1.5 & 4.3 & 3.2 & 9.0 \\
\hline 1 & 1.0 & 3.5 & 4.1 & 8.6 \\
\hline \multicolumn{5}{|c|}{ Stage-I $160^{\circ} \mathrm{C}$} \\
\hline 0 & 1.3 & 4.0 & 5.2 & 10.5 \\
\hline 0.125 & 1.6 & 4.6 & 5.1 & 11.3 \\
\hline 0.25 & 1.5 & 4.3 & 4.7 & 10.5 \\
\hline 0.5 & 1.3 & 4.3 & 4.9 & 10.5 \\
\hline 1 & 1.5 & 4.3 & 4.7 & 10.5 \\
\hline \multicolumn{5}{|c|}{ Stage-I $200^{\circ} \mathrm{C}$} \\
\hline 0 & 1.5 & 4.6 & 6.1 & 12.2 \\
\hline 0.125 & 2.0 & 5.5 & 6.0 & 13.5 \\
\hline 0.25 & 2.0 & 5.5 & 5.8 & 13.3 \\
\hline 0.5 & 2.0 & 6.0 & 6.5 & 14.5 \\
\hline 1 & 1.6 & 5.1 & 6.3 & 13.0 \\
\hline
\end{tabular}

\subsection{Structural Reconstruction and Reinforcement Analysis by FEM}

Based on the dimensional parameters calculated from scattering/diffraction analysis (Tables 3 to 5), the lamellae microstructure is reconstructed to a comparable scale for final stage drawn control and $0.5 \mathrm{wt} \%$ loaded composite fibers (Figures 6a and 6b) [44]. The most distinguished change between these two samples is the differences in single lamella length and width from the control to composite fibers. The overall lamella stack size decreases from control to composites and the number of lamellae within a unit fibril volume also increases proportionally from the control fibers to the composites (Tables 3 to 5). The increases in boundary area per unit volume appear to slow or impede dislocation movement in the fiber making it more resistant to fracture, and the trend in fracture strength 
from the control to the composite (Table 1) is also proportional to the grain size reciprocal [44].

In order to understand the contribution of the crystalline and amorphous regions to mechanical properties and the relationship with nano filler loadings in composite fibers, FEM analysis is used. Models are constructed in order to simulate tensile testing properties within linear elastic regions, as well as examine fracture behavior for the fibrils. These simulations are also helpful toward understanding the intrinsic nano-scale mechanical properties pertaining to the individual crystalline and amorphous components, which are not possible to be obtained experimentally. Experimental limitations are related to difficulty in sample preparation as well as lack of measurement instrumental precision. However, the experimental work here is important for understanding the bulk material properties, while the coupled simulations can help to gain understanding regarding the component behavior (i.e., crystalline and amorphous regions). 

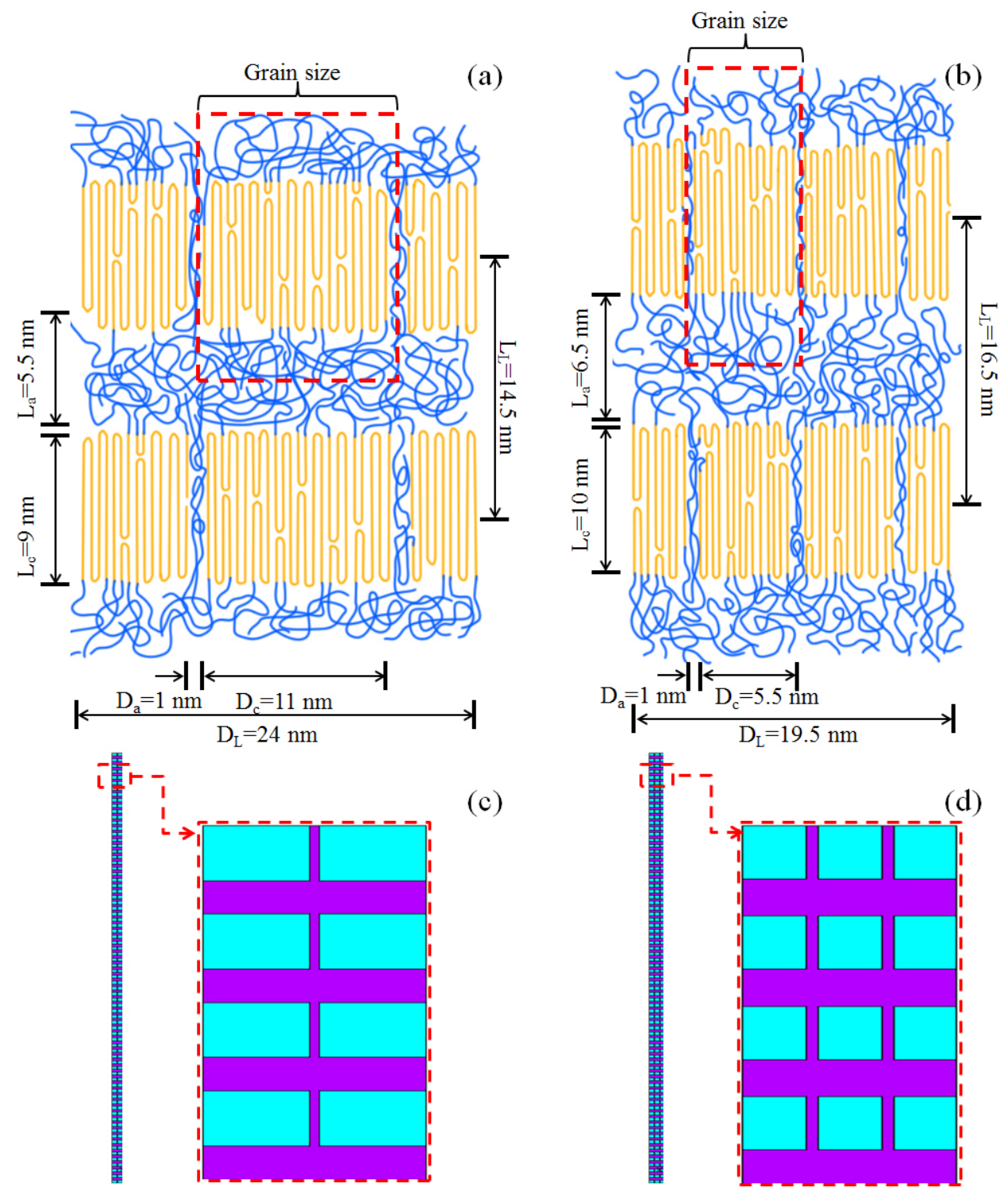

(c)

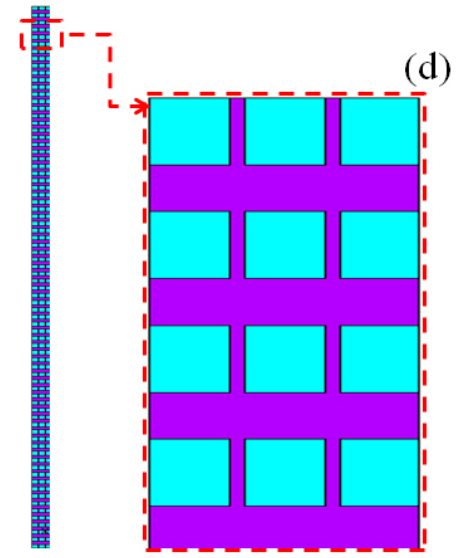

Figure 6. Single lamellae structure with parameters listed for (a) PVA and (b) PVA/CNC composites at $0.5 \mathrm{wt} \%$ loading, indicating alternative regions of either crystalline or amorphous zone. FEM models of partial fibril structures plotted for both (c) PVA and (d) $\mathrm{PVA} / \mathrm{CNC}$ composites as determined using experimental analysis.

The finite element modeling in this study was performed using an ANSYS (version ANSYS 12) package along with APDL. The usage of APDL allows complete programmable control of design/analysis including the component model dimensions, 
material property, meshing density, and constrains/loading applications. For FEM simulations, control and $0.5 \mathrm{wt} \%$ composite PVA/CNC fiber models are shown in Figures 6c and 6d. The specimens are meshed using 8-node elements PLANE82 for precision due to the irregular shape of amorphous region. The convergence of all simulations is carefully examined to ensure that the results are mesh-independent. The densities and Poisson's ratios parameters are listed in the Table 6 for both amorphous and crystalline regions. To differentiate the crystals from the amorphous regions, variations in density, Poisson ratios and also mechanical modulus were used in this study. For this study the model is simplified to be two-dimensional assuming perfect bonding between crystalline and amorphous regions in the fibrils, therefore no shear modulus would be necessary.

Table 6. PVA material property and dimension parameters considered in the finite element analysis.

\begin{tabular}{|c|c|c|c|c|c|c|c|c|}
\hline \multirow{3}{*}{ Materials } & \multirow{3}{*}{$\begin{array}{c}{ }^{a} \rho \\
\left(\mathrm{g} \cdot \mathrm{cm}^{-3}\right) \\
{[54]}\end{array}$} & \multirow{3}{*}{$\begin{array}{c}{ }^{b} \mu \\
{[60]}\end{array}$} & \multirow{3}{*}{$\begin{array}{c}{ }^{c} \mathrm{E} \\
(\mathrm{GPa}) \\
{[54]}\end{array}$} & \multicolumn{5}{|c|}{$\begin{array}{c}\text { Lamellar dimensions }(\mathrm{nm}) \\
(\text { length } \times \text { diameter })\end{array}$} \\
\hline & & & & \multicolumn{5}{|c|}{$\downarrow$ Filler loadings (wt $\%$ ) } \\
\hline & & & & 0 & 0.125 & 0.25 & 0.5 & 1.0 \\
\hline Crystal PVA & 1.345 & 0.45 & $\begin{array}{l}100 \text { to } \\
255\end{array}$ & $9.0 \times 11.0$ & $9.5 \times 9.5$ & $8.5 \times 10.5$ & $10.0 \times 5.5$ & $9.0 \times 7.5$ \\
\hline $\begin{array}{l}\text { Amorphous } \\
\text { before } T_{g}\end{array}$ & 1.269 & 0.3 & 1 to 10 & $5.5 \times 1.0$ & $6.5 \times 1.0$ & $6.0 \times 1.0$ & $6.5 \times 1.0$ & $6.0 \times 1.0$ \\
\hline $\begin{array}{l}\text { Amorphous } \\
\text { after } T_{g}\end{array}$ & - & - & 0.1 to 1 & - & - & - & - & - \\
\hline
\end{tabular}

${ }^{a}$ density, ${ }^{b}$ Poisson's ratio, ${ }^{c}$ modulus.

\subsubsection{Crystalline/amorphous moduli value range inspection}

It has been observed in both experimental tests and simulations that crystals and amorphous regions display moduli of different orders of magnitude (Table 6). To attain the 
experimental bulk properties for control and composite materials, the modulus for both crystalline and amorphous components were assigned by programming. Using this approach a reasonable range of values for the crystalline/amorphous regions were obtained for the various samples (i.e., PVA and PVA/CNC fibers at loadings from 0.125 to $1 \mathrm{wt} \%$ ). For the evaluation of the elastic modulus or crystalline/amorphous system, a small uniform pressure $(0.1 \mathrm{GPa})$ is applied on one surface, while constraining all degrees of freedom (DOF) on the other surface. The fibril displacement is obtained for strain calculations. By the use of Hooke's law for anisotropic material, the effective elastic modulus along fiberaxis is calculated.

Based on the MD simulations (Section 3.2) of the amorphous PVA matrix, the inherent modulus $\left(E_{a}\right)$ for this region is expected to be much lower than $10 \mathrm{GPa}$. However, if these low values (i.e., 1 to $4 \mathrm{GPa}$ ) are used to simulated the control PVA samples (i.e., $E_{a_{-} \text {Control }}<$ $10 \mathrm{GPa}$ ), the final bulk material will be limited to $\sim 26 \mathrm{GPa}$ even with the assumption that the modulus for the crystalline zone $\left(E_{c}\right)$ is perfectly crystalline, defect free, and aligned (i.e., $E_{c_{-} \text {Control }}=225 \mathrm{GPa}$ ). In addition, this predicted value for the control sample is lower than the experimentally measured data (Table 2). For this reason, the smallest value for the effective modulus contribution of the PVA amorphous region is taken to be $10 \mathrm{GPa}$. This value provides a more reasonable prediction for $E_{c}$, where the real system does not exhibit crystalline perfection (Figure 7). However, further refined of $E_{c}$ predictions are also performed in this study. In addition, considering that the physical conformation of amorphous region is less crystallized and less ordered, its modulus can not be on the same order as the crystalline portion (i.e., due the chain ordering). Thus the theoretical value for $E_{a}$ is calculated and restricted up to $11 \mathrm{GPa}$ in the control samples. Therefore, the $E_{a}$ value 
range between 10 to $11 \mathrm{GPa}$ for the FEM simulation (Figure 7). This increase in $E_{a}$ for the control fibers based on FEM as compared to the MD results, suggests that the amorphous region confined by crystalline lamellae plays a role in its property contribution.

The same principle of relating the crystalline and amorphous moduli is used for the composite materials. In these simulations the amorphous values varied for each different filler concentration, where an increase in $E_{a}$ is observed from $0.125 \mathrm{wt} \%$ up to $0.5 \mathrm{wt} \%$ (Figure 7). The $E_{a}$ range for each sample (i) at $0.125 \mathrm{wt} \%$ is 15 to $18 \mathrm{GPa}$; (ii) at $0.25 \mathrm{wt} \%$ is 19 to $25 \mathrm{GPa}$; (iii) at $5 \mathrm{wt} \%$ is 20 to $30 \mathrm{GPa}$; and (iv) at $1.0 \mathrm{wt} \%$ is 18 to $25 \mathrm{GPa}$ (Figure 7). It is observed that with the increase of nano-fillers, the effective contribution from amorphous regions improves correspondingly with the loading percentage. This is consistent with the loading level as well as the dispersion quality. This analysis shows that the nano-fillers act as constraints limiting the movement of local polymer molecules. However, due to a decrease in filler dispersion level (observed experimentally) for the 1.0 wt $\%$ samples, a decrease of the $E_{a}$ contribution was also observed.

In general for this analysis it is observed that when the amorphous region has low effective modulus values (i.e., 10 and $11 \mathrm{GPa}$ in control fibers), increasing the crystalline mechanical modulus does not efficiently induce property improvement. For example, in the control fiber, a $50 \mathrm{GPa}$ increase in crystalline modulus from $200 \mathrm{GPa}$ to $250 \mathrm{GPa}$ only improves the final bulk material property by 1 to $2 \mathrm{GPa}$. This has significant implications for the polymer fiber material design in terms of microstructural control. It was found here that once the amorphous region achieves or exceeds certain stiffness, the high-performance properties of the material are more efficiently obtained. 


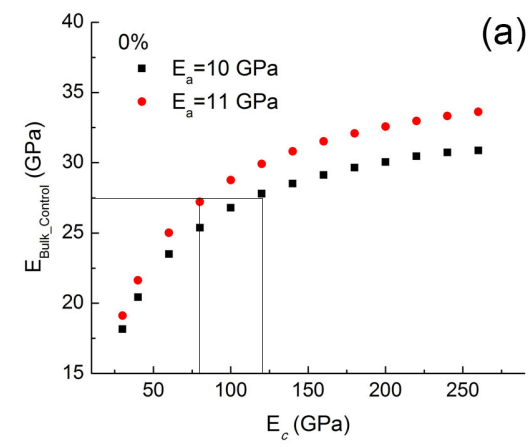

(b)

(c)
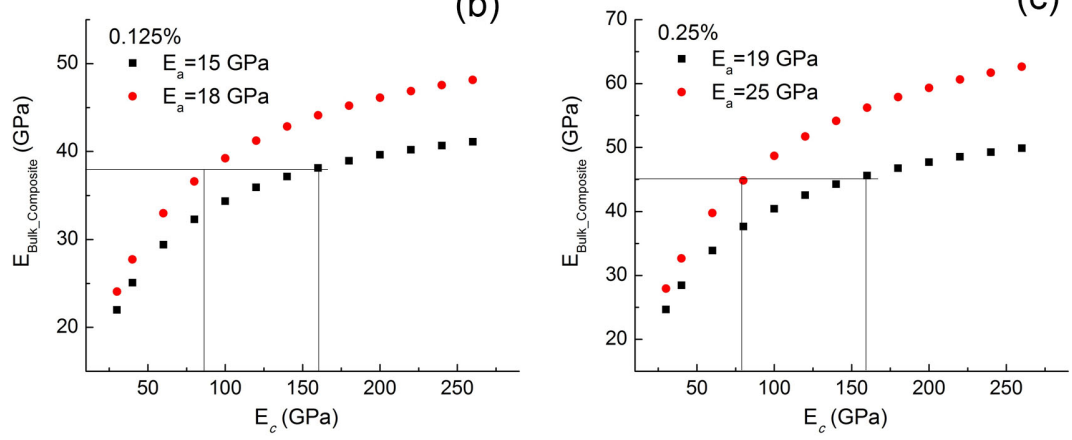

(d)
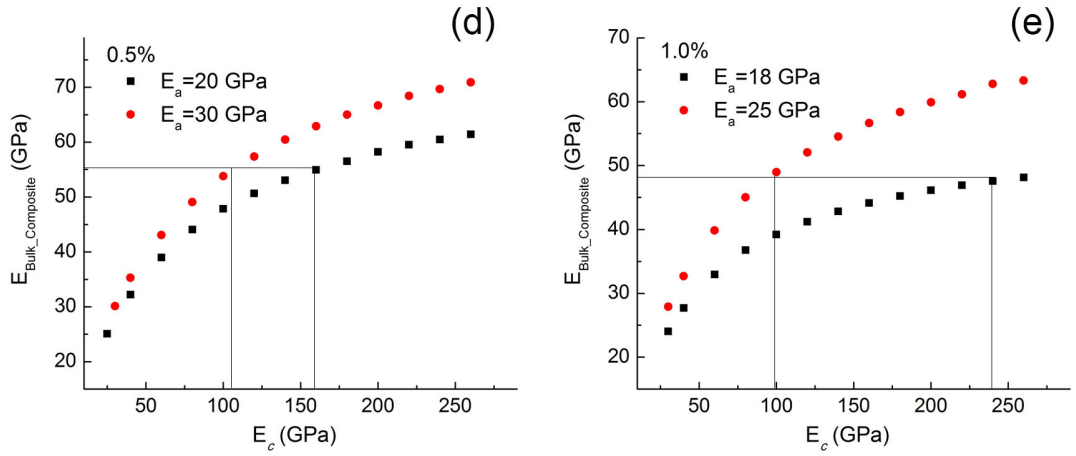

Figure 7. Effective modulus range determination of both amorphous and crystalline regions for bulk (a) control and ( $b$ to e) composites fibers at various loadings.

\subsubsection{Crystalline/amorphous moduli quantification}

To further quantify the possible specific properties of crystalline/amorphous regions, the representative fibrils from the control and composite samples were built and fractured using FEM in order to compare with experimentally obtained values for the fibers. This is reasonable considering that the fibrillar structure in the processed fiber is expected to 
contribute most predominantly to the resultant experimental properties measured. Experimental tensile stress measurements for the polymer fiber are taken at the fracture point. For this reason, the fracture strain is used in the simulation analysis along with an element birth/death method. This approach can be used to deactivate or reactivate selected elements in cases such as staged construction or destruction, as well as sequential assembly or disassembly based on step-wise locations or properties. The $E_{a}$ and $E_{c}$ pairings shown in Figure 7 are used in this analysis. For the control fiber, it is found that with a $E_{a}$ value of 11 $\mathrm{GPa}$, the final tensile strength increased to $1.2 \mathrm{GPa}$ (Figure 8a). The experimental stressstrain curve was also plotted for comparison with the simulation results. Based on this analysis it has been found that $E_{c}$ of $\sim 120 \mathrm{GPa}$ for crystalline regions. This value is also more reasonable considering that the real microstructure (i.e., semi-crystalline) would include a transition zone spanning between the amorphous and crystalline region. For this reason, the crystalline portion in the fiber would exhibit a lower modulus value than the perfectly aligned and crystalline predictions (i.e., $E_{c_{-} \text {Control }}=225 \mathrm{GPa}$ ).

For both control and composite fibers, the crystalline regions are believed to act more as rigid bodies than the amorphous regions. Therefore crystalline modulus was fixed to be constant among all fibers (i.e., $E_{c}$ of $\sim 120 \mathrm{GPa}$ ) and FEM simulations were conducted for all materials to examine the specific $E_{a}$ values using Equations 10 and 11. Based on the equations, $E_{a}$ was determined for all fibers and shown in Figure $8 \mathrm{~b}$.

$$
\begin{aligned}
& E_{\text {Composite }}=E_{\text {Bulk_}_{-} P V A} V_{P V A}+E_{C N C} V_{C N C} \\
& E_{\text {Bulk_PVA }}=E_{c} V_{c}+E_{a} V_{a}
\end{aligned}
$$


It was observed in fracture simulations that the effective amorphous modulus contribution for composites increased with loadings and ranged from 15, 20, 25, and 20 GPa for $0.125,0.25,0.5$, and $1.0 \mathrm{wt} \%$ filler loadings, respectively (Figure $8 \mathrm{c}$ ). As discussed this analysis verifies the ability of the nano-filler to act as a constraint hindering local motion of the polymer component under load (Figure 8c). Figure 8d provides a schematic based on the experimental dimensions of the lamellae and fillers after dispersion, illustrating that the amorphous regions are large enough to accommodate well-dispersed nano-carbons, which would allow for constraint of polymer motion.
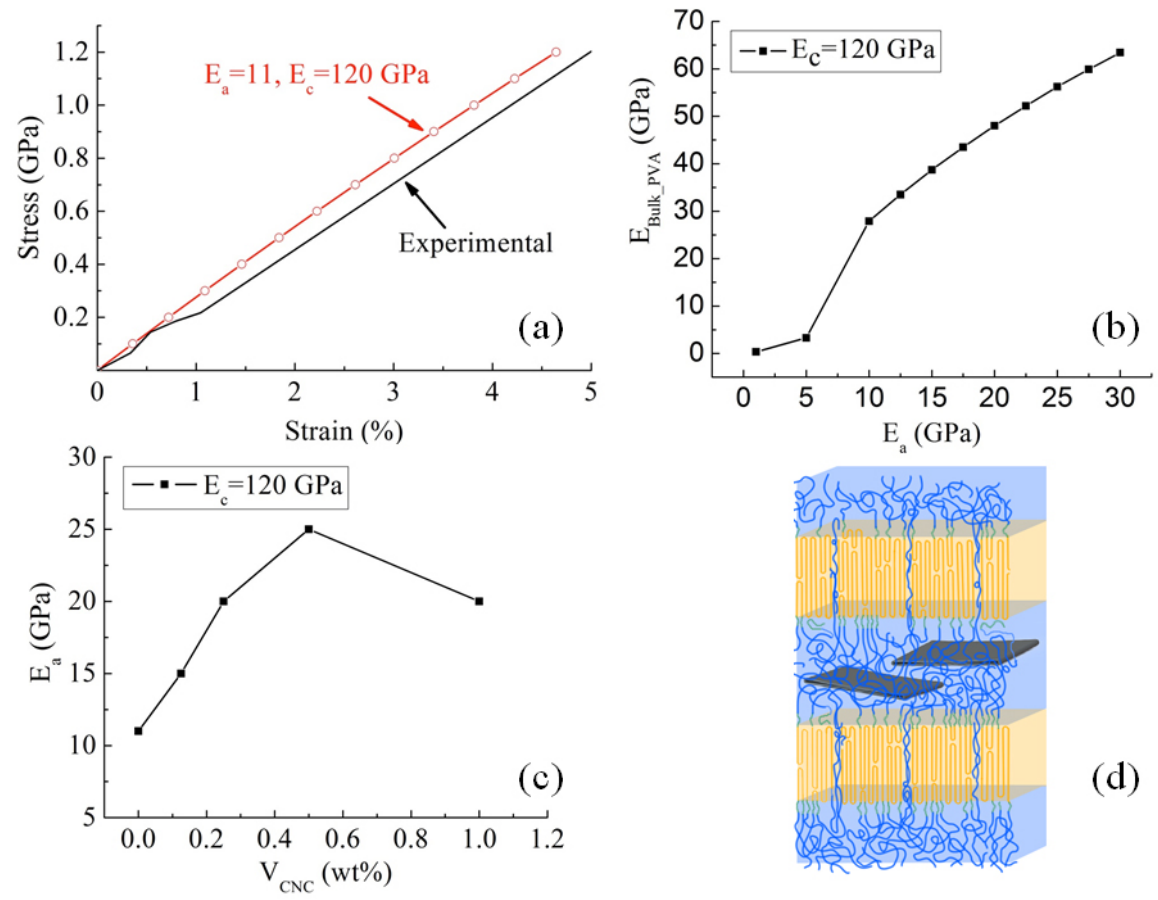

(d)

Figure 8. (a) Simulated and experiment comparison for the fracture of the control fibers to determine the quantitative stress-strain relationship. (b) Solution of the amorphous modulus (i.e., $E_{c}$ of $120 \mathrm{GPa}$ ) contribution based on FEM and experimental comparison. (c) $E_{a}$ approximation of the fibers as a function of filler content. (d) Schematic of constraining amorphous regions by rigid nanoparticles. 


\section{Conclusions}

The key factors that dominate the reinforcement mechanism in nano-composites require a thorough understanding of filler dispersion at the nanoscale, polymer chain and/or nanofiller morphology, as well as the molecular level interactions between nano-filler and polymer matrix. In-depth analysis of the fiber microstructure by correlating X-ray scattering and SEM have shown more highly aligned polymer chains, more perfectly formed fibrillar structures, and longer lamellae spacing in the composites as compared to the control fibers. SAXS based correlation function calculations also showed that composite fibers exhibit more grains (i.e., lamellae) per unit volume of the fibrils. This leads to both modulus and strength enhancement due to the impedance of dislocation movement through the material when stress is applied. The simulation outcomes in this study provide fundamental understanding regarding the role of nano-fillers in the polymer composites to aid polymer component constraining. For this reason, low loadings of nanofillers can result in significant improvements in the mechanical properties (i.e., modulus, strength and toughness) of composite fibers well beyond theoretical predictions.

\section{Acknowledgements}

Financial support of this work was provided by Air Force Office of Scientific Research (AFOSR) (FA9550-11-1-0153) and the National Science Foundation (NSF CMMI1351657). 


\section{References}

1. Zhang SJ and Kumar S. Small 2008;4(9):1270-1283.

2. Dai HJ. Surface Science 2002;500(1-3):218-241.

3. Baughman RH, Zakhidov AA, and de Heer WA. Science 2002;297(5582):787-792.

4. Wang CC, Guo ZX, Fu SK, Wu W, and Zhu DB. Progress in Polymer Science 2004;29(11):1079-1141.

5. Sahoo NG, Rana S, Cho JW, Li L, and Chan SH. Progress in Polymer Science;35(7):837-867.

6. Kuilla T, Bhadra S, Yao DH, Kim NH, Bose S, and Lee JH. Progress in Polymer Science 2010;35(11):1350-1375.

7. Spitalsky Z, Tasis D, Papagelis K, and Galiotis C. Progress in Polymer Science 2009;35(3):357-401.

8. $\quad$ Szleifer I and Yerushalmi-Rozen R. Polymer 2005;46(19):7803-7818.

9. Green MJ, Behabtu N, Pasquali M, and Adams WW. Polymer 2009;50(21):4979-4997.

10. Fujigaya $T$ and Nakashima $N$. Journal of Nanoscience and Nanotechnology 2012;12(3):1717-1738.

11. Huang Z-M, Zhang YZ, Kotaki M, and Ramakrishna S. Composites Science and Technology 2003;63(15):2223-2253.

12. Swain SK and Jena I. Asian Journal of Chemistry 2011;22(1):1-15.

13. Derek Hull and Clyne TW. Introduction to Composite Materials, 2nd ed. Cambridge: Cambridge University Press, 1996.

14. Halpin JC. Effects of environmental factors on composite materials. 1969.

15. Mallick PK. Firber-Reinforced Composites: Materials, Manufacturing and Design, 2nd ed. New York: Marcel Dekker, Inc., 1993.

16. Song K, Zhang Y, Meng J, Green E, Tajaddod N, Li H, and Minus M. Materials 2013;6(6):2543-2577.

17. Putz KW, Mitchell CA, Krishnamoorti R, and Green PF. Journal of Polymer Science Part B: Polymer Physics 2004;42(12):2286-2293.

18. Xu X, Thwe MM, Shearwood C, and Liao K. Applied Physics Letters 2002;81(15):2833-2835.

19. Ko F, Gogotsi Y, Ali A, Naguib N, Ye H, Yang GL, Li C, and Willis P. Advanced Materials 2003;15(14):1161-1165.

20. Cadek M, Coleman JN, Ryan KP, Nicolosi V, Bister G, Fonseca A, Nagy JB, Szostak K, Beguin $F$, and Blau WJ. Nano Letters 2004;4(2):353-356.

21. Xu X, Uddin AJ, Aoki K, Gotoh Y, Saito T, and Yumura M. Carbon 2010;48(7):1977-1984.

22. Dong J, Yin C, Zhao X, Li Y, and Zhang Q. Polymer 2013;54(23):6415-6424.

23. Andrews $R$, Jacques $D$, Rao AM, Rantell $T$, Derbyshire $F$, Chen $Y$, Chen J, and Haddon RC. Applied Physics Letters 1999;75(9):1329-1331.

24. Bhuiyan MKH, Rahman MM, Mina MF, Islam MR, Gafur MA, and Begum A. Composites Part A: Applied Science and Manufacturing 2013;52(0):70-79.

25. Fu S-Y, Feng X-Q, Lauke B, and Mai Y-W. Composites Part B: Engineering 2008;39(6):933961.

26. Garapati SH and Kaw A. Composite Interfaces 2011;18(3):275-294.

27. Pang HA, Chen C, Zhang YC, Ren PG, Yan DX, and Li ZM. Carbon 2011;49(6):1980-1988.

28. Istrate OM, Paton KR, Khan U, O'Neill A, Bell AP, and Coleman JN. Carbon 2014;78(0):243249.

29. Liu Y and Kumar S. Acs Applied Materials \& Interfaces 2014;6(9):6069-6087. 
30. Mittal G, Dhand V, Rhee KY, Park S-J, and Lee WR. Journal of Industrial and Engineering Chemistry 2014;1(1):1-15.

31. Meng J, Zhang Y, Cranford SW, and Minus ML. The Journal of Physical Chemistry B 2014;118(31):9476-9485.

32. Vonk C. Colloid and Polymer Science 1979;257(10):1021-1032.

33. Jin L, Ball J, Bremner T, and Sue H-J. Polymer 2014;55(20):5255-5265.

34. Shi S, Pan Y, Lu B, Zheng G, Liu C, Dai K, and Shen C. Polymer 2013;54(25):6843-6852.

35. Tang Y, Jiang Z, Men Y, An L, Enderle H-F, Lilge D, Roth SV, Gehrke R, and Rieger J. Polymer 2007;48(17):5125-5132.

36. Men $\mathrm{Y}$, Rieger J, Lindner $\mathrm{P}$, Enderle $\mathrm{H}-\mathrm{F}$, Lilge $\mathrm{D}$, Kristen $\mathrm{MO}$, Mihan $\mathrm{S}$, and Jiang $\mathrm{S}$. The Journal of Physical Chemistry B 2005;109(35):16650-16657.

37. Wang W, Murthy NS, and Grubb DT. Polymer 2007;48(12):3393-3399.

38. Imai M, Kaji K, and Kanaya T. Macromolecules 1994;27(24):7103-7108.

39. Perret E, Reifler FA, Hufenus R, Bunk $O$, and Heuberger M. Macromolecules 2012;46(2):440-448.

40. Murthy NS and Grubb DT. Journal of Polymer Science Part B: Polymer Physics 2002;40(8):691-705.

41. Samon JM, Schultz JM, and Hsiao BS. Polymer 2000;41(6):2169-2182.

42. Murthy NS, Bednarczyk C, Moore RAF, and Grubb DT. Journal of Polymer Science Part B: Polymer Physics 1996;34(5):821-835.

43. Wu J, Schultz JM, Samon JM, Pangelinan AB, and Chuah HH. Polymer 2001;42(16):71617170.

44. Song $\mathrm{K}$, Zhang $\mathrm{Y}$, and Minus ML. Macromolecular Chemistry and Physics 2015;216(12):1313-1320.

45. Song K, Zhang $\mathrm{Y}$, Meng J, and Minus ML. Journal of Applied Polymer Science 2012;127(4):2977-2982.

46. Minus ML, Chae HG, and Kumar S. Macromol Rapid Comm 2010;31(3):310-316.

47. Minus ML, Chae HG, and Kumar S. Macromolecular Chemistry and Physics 2009;210(21):1799-1808.

48. Lee JG. Computational Materials Science: An Introduction. Boca Raton, FL: Talor \& Fracis Group, LLC, 2011.

49. Treloar LRG. Polymer 1960;1(0):290-303.

50. Treloar LRG. Polymer 1960;1(0):279-289.

51. Treloar LRG. Polymer 1960;1(0):95-103.

52. Manley TR and Martin CG. Polymer 1973;14(10):491-496.

53. Hearle JWS, Prakash R, and Wilding MA. Polymer 1987;28(3):441-448.

54. Sakurada I. Polyvinyl Alcohol Fibers. New York: Marcel Dekker, Inc., 1985.

55. Sakurada I, Nukushina Y, and Ito T. Journal of Polymer Science 1962;57(165):651-660.

56. Sakurada I, Ito T, and Nakamae K. Die Makromolekulare Chemie 1964;75(1):1-10.

57. Reith D, Meyer H, and Muller-Plathe F. Macromolecules 2001;34(7):2335-2345.

58. Salem DR. Structure Formation in Polymeric Fibers, $1^{\text {st }}$ ed. Cincinnati, $\mathrm{OH}$ : Hanser Gardner Pubns, 2000.

59. Scherrer P. Abgeschätzt aus den Linienbreiten des Beugungsdiagramms nach der Formel von Scherrer, 1918.

60. Kumar P and Srinivas J. Computational Materials Science 2014;88(0):139-144. 


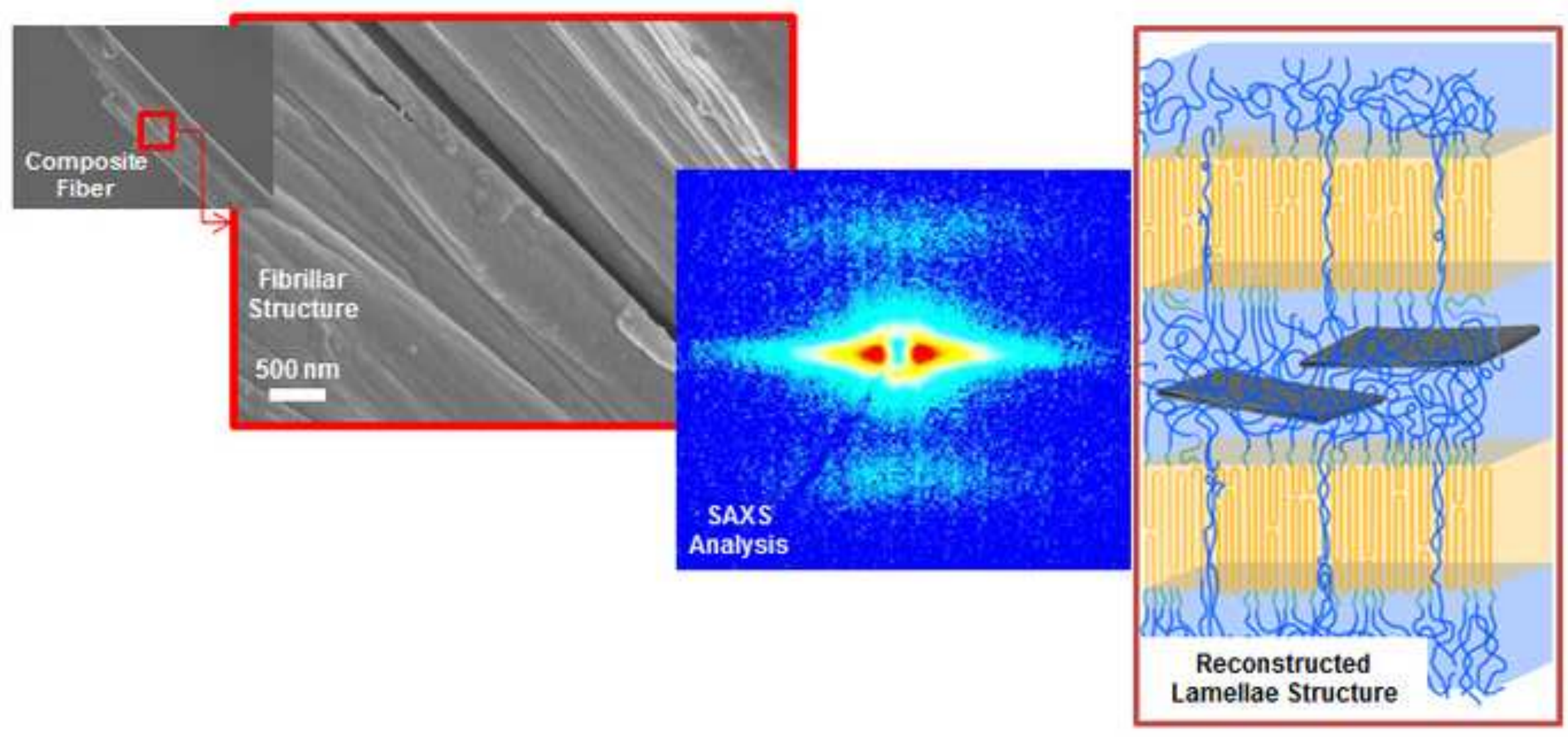

SAXS
Analysis

amellae Structure 